\title{
Mastoid abscess as a presenting complaint of Kostmann syndrome in childhood.
}

\author{
Ramadan said. Ahmed Ismail. Khaled Gamal dahy. Arafat Mohamed. \\ Farghali Mikki. \\ Department of Ear, Nose and Throat at the Faculty of Medicine, Sohag University
}

\begin{abstract}
Kostmann disease is a rare born-with disorder seen as extreme neutropenia due to abnormally low myeloid differentiation in the bone marrow, with the neutrophil count being less than 500_103 cells/l. Male child 4.5-year old complains from a bilateral aural discharge of 2 years duration. By examination, there is a gapped post auricular wound with necrosis in parts and inflamed lower part of the mastoid and upper part of the neck, and bilateral central tympanic membrane perforation with pulsating discharge. Hematological investigations were done that reveal severe neutropenia (Kossmann disease). Canal wall down (CWD) mastoidectomy with wide meatoconchoplasty for exteriorization of the cavity was done. Removal of infected tissues in the postauricular region, the undermining of skin and primary repair was done in two layers. After that, ear discharge and postauricular swelling improved and patient with good general condition with an excellent outcome. So, a mastoid abscess can be a presenting complaint of Kostmann disease.
\end{abstract}

Keywords: Mastoid abscess, Kossmann disease, Neutropenia.

\section{Introduction}

Kostmann disease is a rare born-with disorder seen as extreme neutropenia due to abnormally low myeloid differentiation in the bone marrow, with the neutrophil count being less than 500_103 cells/1 [1]. Increased incidence of bacterial infections is the most presenting sign of this disease. The first infection happens shortly after birth. Immunodeficiency with severe neutropenia leads to abscess formation. Abscesses happen in different parts of the body: ear, skin, scalp, and lung. The most common microorganisms are mainly endogenous flora, such as Staph. aureus, E. coli, and pseudomonas. The current treatment for this disease is long term treatment with recombinant human granulocyte colony-stimulating factor (G-CSF). Most complications of this disease are due to infections but about $9 \%$ of patients develop serious disorders: acute myeloid leukemia [2]. We present a case of Kostmann disease with recurrent skin infections and bilateral chronic suppurative otitis media complicated with right mastoid abscess.

\section{Case presentation}

Male child 4.5-year old complains from a bilateral aural discharge of 2years duration, yellowish, offensive, mucopurulent, not improving on medication, and associated with highgrade fever. There is no history of vertigo, facial asymmetry, or other symptoms suggesting cranial or intracranial complications. He has a history of recurrent postauricular abscess 3 times within the previous year, incision and drainage were done only with antibiotics and patient 
improved, also has a history of multiple skin abscesses in the whole body, incision, and drainage was done. No history of trauma or operations, there is a history of repeated blood and plasma transfusion. There is a history of regular drug intake weekly (Neupogen) subcutaneously as the child is known to have severe congenital neutropenia (Kossmann disease) since the age of 3 months old. Parents have positive 1st-degree consanguinity and no family history of similar conditions. By examination, there are multiple skin scars, gapped post auricular wound with necrosis in parts and inflamed lower part of mastoid and upper part of the neck (fig 1), and bilateral pinhole central perforation with pulsating discharge. Normal cranial nerve examinations. Hematological investigations were done that reveal severe neutropenia (Kossmann disease) (fig 2).
Radiological investigations were done that reveal granulation tissue filling mastoid and middle ear cavity eroding mastoid cortex and rarefying sinus plate with intact ossicular chain (fig 3,4). Audiological investigations were done that reveal bilateral mild conductive hearing loss with a perforated drum. Patient prepared for right ear exploration that reveals infected granulation tissue filling all mastoid air cells, eroding sinus plate with exposed sinus, extending through aditus, and wrapping ossicles. Canal wall down (CWD) mastoidectomy with wide meatoconchoplasty for exteriorization of the cavity was done. Removal of infected and necrosed tissues in the postauricular region, undermining of skin and primary repair was done in two layers (fig 5). A biopsy was taken for histopathological examination reveals a florid suppurative inflammatory process.

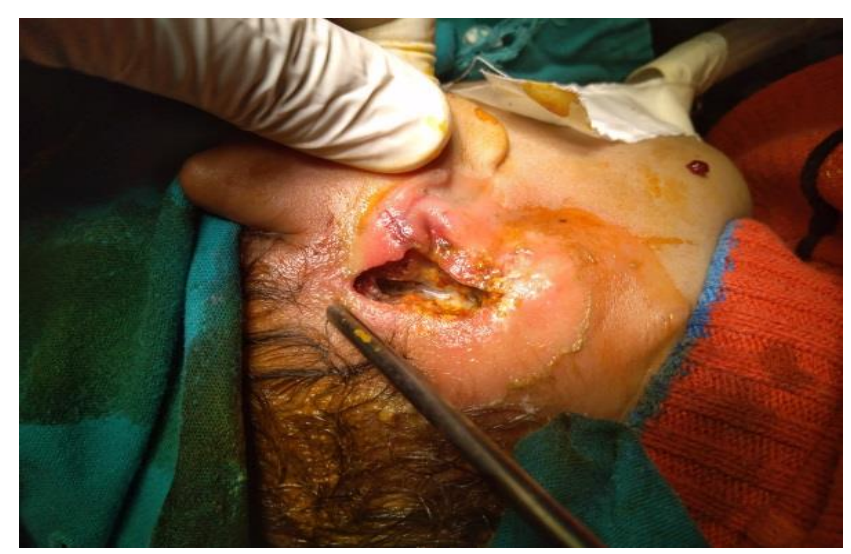

Fig(1).drainage of the mastoid abscess with the postauricular incision under GA.

\begin{tabular}{|c|c|c|c|}
\hline \multicolumn{2}{|c|}{ Resu lt } & Flags & Un it \\
\hline $\begin{array}{l}\text { WJBC } \\
\text { LYM } \\
\text { MID } \\
\text { GRA } \\
\text { LYMY\% } \\
\text { MID\% } \\
\text { GRA\% }\end{array}$ & $\begin{array}{l}9.6 \\
5.3 \\
2.4 \\
1.9 \\
55.0 \\
25.3 \\
19.7\end{array}$ & $\begin{array}{l}\mathrm{H} \\
s \mathrm{H} \\
\mathrm{sH} \\
\mathrm{sH} \\
\mathrm{sH} \\
\mathrm{sH} \\
\mathrm{sH}\end{array}$ & $\begin{array}{l}10^{\wedge} 3 / \mu L \\
10^{\wedge} 3 / \mu L \\
10^{\wedge} 3 / \mu L \\
10^{\wedge} 3 / \mu L \\
\% \\
\% \\
\%\end{array}$ \\
\hline $\begin{array}{l}\text { RBC } \\
\mathrm{HGB} \\
\mathrm{HCT} \\
\mathrm{MCU} \\
\mathrm{MCH} \\
\mathrm{MCHC} \\
\text { RDW }\end{array}$ & $\begin{array}{r}3.48 \\
8.3 \\
25.7 \\
73.9 \\
23.9 \\
32.3 \\
23.7\end{array}$ & $\begin{array}{l}\mathrm{H} \\
\mathrm{H} \\
\mathrm{H} \\
\mathrm{H} \\
\mathrm{H} \\
\mathrm{H} \\
\mathrm{H}\end{array}$ & $\begin{array}{l}10^{\wedge} 6 / \mu L \\
g / d L \\
\% \\
f L \\
p g \\
g / d L \\
\%\end{array}$ \\
\hline $\begin{array}{l}\text { PLT } \\
\text { MPU }\end{array}$ & $\begin{array}{l}459 \\
8.3\end{array}$ & $\begin{array}{l}\mathrm{H} \\
\mathrm{H}\end{array}$ & $\begin{array}{l}10^{\wedge} 3 / \mu L \\
f L\end{array}$ \\
\hline
\end{tabular}

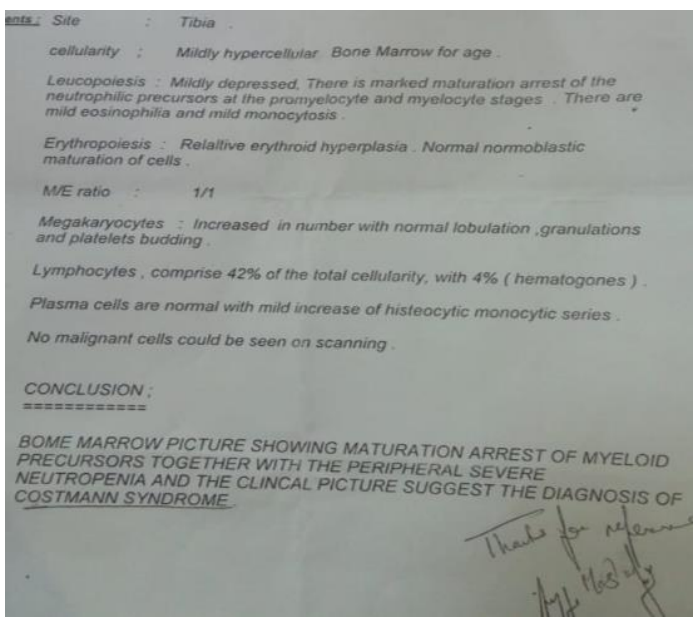


SOHAG MEDICAL JOURNAL

Vol. 24 No. 2 April 2020
Mastoid abscess as a presenting complaint Farghali mekki

Fig(2).Haematological evaluation for diagnosis of Kostmann syndrome.

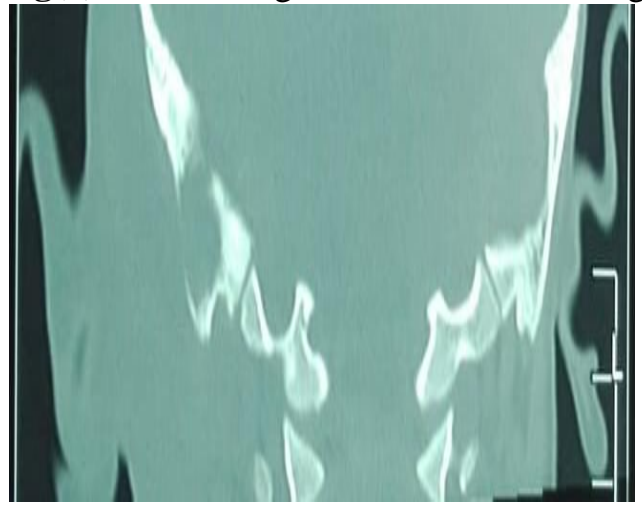

Fig(3).CT temporal coronal cuts show soft tissue density in the mastoid and destruction of lateral mastoid cortex \& tegmen antri with subcutaneous abscess.
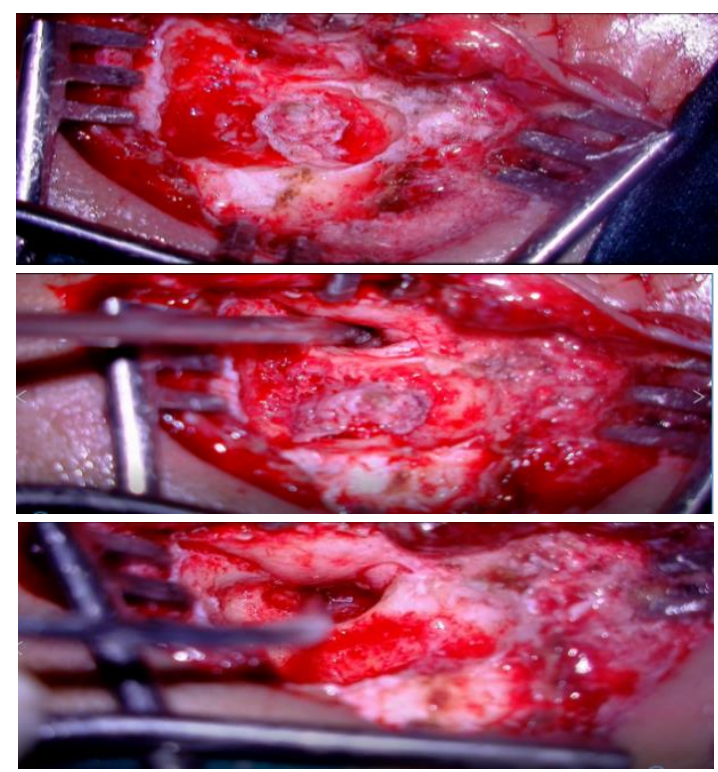

Fig (5) Operative findings show granulation tissues in the mastoid cavity (1) extended to the attic wrapping the ossicles (2) and ME cavity (3) .radical mastoidectomy (4) was done with the clearance of ET orifice(5).double aeration of mastoid was done (6)
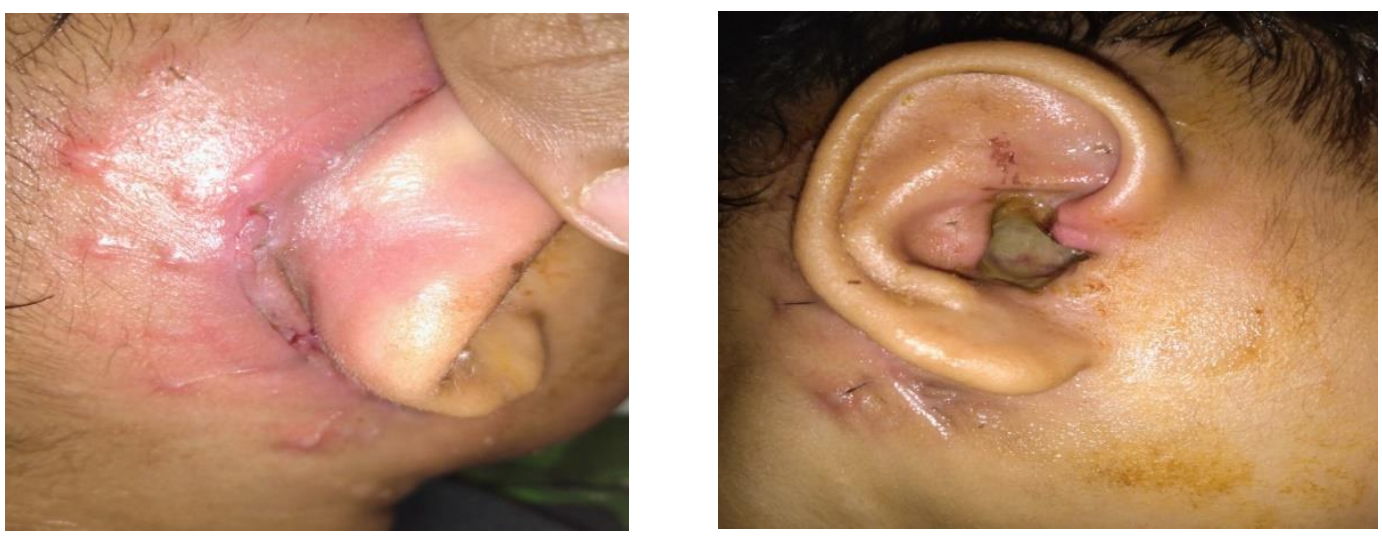
Fig (6) post-operative findings of healed postauricular wound and healed ME and mastoid cavity.

\section{Discussion}

Rolf Kostmann is the first scientist who describes severe congenital neutropenia in 1956 [3]. Kostmann named this disease infantile genetic agranulocytosis. Now, it is known as Kostm-ann disease or severe congenital neutropenia [4]. Although Kostmann was able to show that the blood dyscrasia was an autosomal recessive manner, the underlying genetic defect responsible for the agranulocytosis was not explained until recently. Now, we know that a mutation of the gene that encodes the hematopoietic cell-specific LYN substrate 1-associated protein $\mathrm{X} 1$ (HAX1) is responsible for the developent of this autosomal arrest in neutronphil maturation and decreased the production of neutrophils that are obvious in patients with Kostmann disease [5].

Long-term treatment with hematopoietic growth factor (recombinant human G-CSF) is the current treatment for this disease. It is used to increase neutrophil counts to the normal range and reduce the incidence of infections. Prophylactic antibiotics are not usually needed [1]. Otitis media is a common childhood infection that may result from a variety of predisposing factors. Immunodeficiency is one of these predisposing factors and should be suspected when otitis media is recurrent; suppurative; not responding to antibiotics; caused by uncommon microorganisms; severe eczema, or failure to thrive. The immune deficiencies most likely to cause increased otitis media are humoral immune deficiencies that produce antibody to encapsulated microorganisms. Complications of otitis media, such as acute mastoiditis and chronic suppurative otitis media are more suggestive of an immune deficiency than recurrent otitis media. This is just like our case where he is presented by multiple skin abscesses in the whole body with mastoid abscess and persistent otitis media unresponsive to antibiotics. Evaluation of the immune system should focus on humeral immunodeficiency diseases, however, the presenting complaint and physical signs also should be considered when designing the work-up. Treatment of the underlying immune deficiency is usually essential to adequately treat otitis media [6]. One of the worst phagocytic defects is Kostmann disease, which associated with severe recurrent or chronic otitis media. The other common infections were skin abscess, pneumonia, oropharyngeal ulceration, gastroenteritis, and oral moniliasis. Less common infections were rhinosinusitis, mucopurulent conjunctivitis, CNS infections, and osteomyelitis [7]. Other common causes as anatomical verities, allergy, and daycare exposure should be excluded before starting an immunodeficiency workup in children with recurrent otitis media. History taking to evaluate the number of episodes, severity, and duration of each one and its response to antibiotics is necessary for all immune deficiency evaluations. Looking for other associated infections as a skin abscess, gastroenteritis, microorganisms cultured, and growth problems help develop another possible diagnosis. The clinician should search for physical findings, such as ear discharge, eczema, and evidence of failure to thrive. In the child complaining of recurrent otitis media for which other possible causes have been excluded, an immunoglobulin's profile, a complete blood picture with differential count and specific antibodies should be done (Table 1) [8]. 


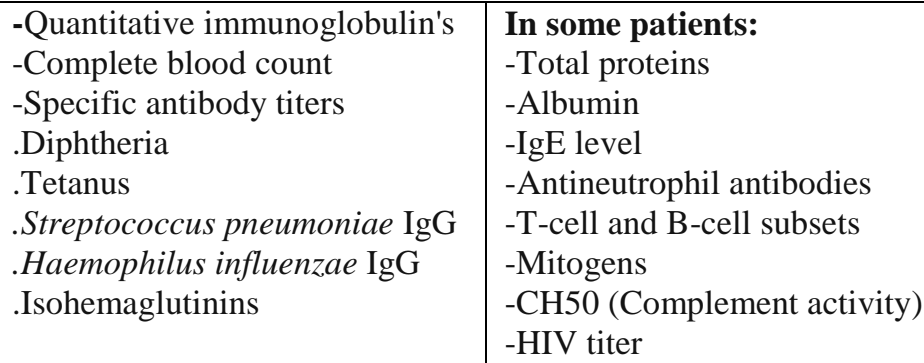

Table1. Evaluation for immunodeficiency in patients with frequent otitis media
Treatment of otitis media in patients with immune deficiencies should be aggressive than that in other healthy patients, which was consistent with our management of this case where canal wall down (CWD) mastoidectomy with wide meatoconchoplasty for exteriorization of the cavity was done. Cultures from myringotomy with identification of microorganisms and its sensitivity to antibiotics help in antibiotic selection, early starting of intravenous antibiotic therapy and hospital admission. Follow up and prophylaxis against complications of suppurative otitis media as acute mastoiditis, and application of ear ventilation tubes is usually needed. Continuous or intermitent antibiotics have been used to decrease the number of episodes of ear infections in a variety of immune deficiencies [9]. We performed CWD mastoidectomy with wide meatoconchoplasty for chronic suppurative otitis media complicated with a mastoid abscess in a child diagnosed with Kossmann syndrome, after that, ear discharge and postauricular swelling improved and patient with good general condition with an excellent outcome.

\section{References}

1. Zeidler, C., et al., Management of Kostmann syndrome in the G-CSF era. British journal of hematology, 2000. 109(3): p. 490-495.

2. Klein, C., et al., HAXI deficiency causes autosomal recessive severe congenital neutropenia (Kostmann disease). Nature genetics, 2007. 39(1): p. 86.

3. Kostmann, R., Infantile genetic agranulocytosis (agranulocytosis infantilism hereditary) a new recessive lethal disease in man. Acta paediatrica, 1956. 45(3): p. 309-310.

4. Carlsson, G. and A. Fasth, Infantile genetic agranulocytosis, Morbus Kostmann: presentation of six cases from the original "Kostmann family" and a review. Acta Paediatrica, 2001. 90(7): p. 757-764.

5. Melin, M., et al., Assignment of the gene locus for severe congenital neutropenia to chromosome $1 q 22$ in the original Kostmann family from Northern Sweden. Biochemical and biophysical research communications, 2007. 353(3): p. 571-575.

6. Wilson, N.W. and M.B. Hogan, Otitis media as a presenting complaint in childhood immunodeficiency diseases. Current Allergy and asthma reports, 2008. 8(6): p. 519-524.

7. Rezaei, N., et al., Congenital neutropenia and primary immunodeficiency disorders: a survey of 26 Iranian patients. Journal of pediatric hematology/oncology, 2005. 27(7): p. 351-356.

8. Ogershok, P.R., et al., Spectrum of illness in pediatric common variable immunodeficiency. Annals of Allergy, Asthma \& Immunology, 2006. 97(5): p. 653-656.

9. Leach, A.J. and P.S. Morris, Antibiotics for the prevention of acute and chronic suppurative otitis media in children. Cochrane Database of Systematic Reviews, 2006(4). 